\title{
Biomass pyrolysis kinetics and impact of volatile products for slagging
}

\author{
Guanzhong Sun ${ }^{1, a}$, Shanshan He ${ }^{1, b}$, Hongliang Zhang ${ }^{2, c}$, Wei $\mathrm{Li}^{1, \mathrm{~d}^{*}}$ \\ ${ }^{1}$ North China Electric Power University the Key Laboratory of Regional Energy System Optimization, \\ Beijing 102206, China \\ ${ }^{2}$ Guangdong Power Grid Ltd. Electric Power Research Institute, Guangdong Guangzhou, 510600, \\ China \\ asgzncepu@gmail.com, bhduhss@126.com, gzmeihualu@163.com, weili81927@163.com
}

Keywords: biomass; TG-DTG-FTIR; Flynn-Wall-Ozawa method; the maximum weight loss rate; characteristic peaks; slagging.

Abstract. Basing on TG-DTG-FTIR technology, researching about kinetic activation energy E about eucalyptus and absorption bands and characteristic peaks of volatile product under the heating rate $10^{\circ} \mathrm{C} \cdot \min ^{-1}, 30^{\circ} \mathrm{C} \cdot \min ^{-1}, 60^{\circ} \mathrm{C} \cdot \min ^{-1}$ respectively. The experimental results show that eucalyptus pyrolysis process can be divided into 3 stages: moisture volatilizes stage $\left(0-265^{\circ} \mathrm{C}\right)$, volatility analysis phase $\left(265-605^{\circ} \mathrm{C}\right)$ and carbonization stage $\left(605-700^{\circ} \mathrm{C}\right)$. And with the increasing of the heating rate, the maximum weight loss rate increased. the initial pyrolysis temperature $\left(T_{i n}\right)$, the termination of pyrolysis temperature $\left(T_{h}\right)$ and the maximum peak temperature $\left(T_{\max }\right)$ of the pyrolysis curves slightly moved to the high temperature areas. Flynn-Wall-Ozawa integral method can calculate activation energy $\mathrm{E}$ value of eucalyptus under the conversion rate $\in[0.2,0.8]$ even through the reaction mechanism is an unknown function. Its value is between 33.25 and $60.12 \mathrm{~kJ} \cdot \mathrm{mol}^{-1}$, which has little difference from $\mathrm{C}-\mathrm{R}$ method for solving activation energy $\mathrm{E}$ value of eucalyptus. Finally, the pyrolysisproduct was analyzed by using the FTIR spectra. What's more, it can verify its corresponding TG-DTG curve. The experiment aims to study the biomass which cause material agglomerate, furnace coke, fouling and equipment corrosion in the process of burning, so that it can provide theoretical support.

\section{Introduction}

Biomass is widely considered to be a kind of "zero $\mathrm{CO}_{2}$ emissions" environmentally friendly and renewable energy. Burning biomass has the less emission of sulfur oxide and nitrogen oxide than conventional fossil fuel at the same time of low emission of $\mathrm{CO}_{2}$, because the content of $\mathrm{S}$ and $\mathrm{N}$ is low. The production of rural biomass is about 30 billion tons per year all over the world. Biomass energy consumption can account for $14 \%$ of the world's energy, second only to oil, coal and natural gas. As biomass is a renewable, potential of sustainable and relative environmentally friendly clean energy, we intensify the efforts on the development and utilization of renewable biomass in China[1-5]. At present, the domestic and foreign researchers have made a lot of research on kinetics and the character of volatile product of biomass, and achieve a certain progress and results. Sharma et al. studied the behavior of rice husk in the state of pellet and powder. The kinetic parameters were determined. Chen Wei et al. used thermogravimetric-differential scanning thermal analyzer to do the pyrogenation experiments of rice straw. They discussed the basic pyrogenation process of rice straw in detail and established the optimal dynamic mechanism model through comparing and analyzing the curve of DTG and DSC. Wangshuang et al. used the TG-FTIR hyphenated techniques to study the pyrogenation process and kinetics of marine algae gracilaria. They calculated the pyrogenation product release index and obtained the kinetic compensation effect between activation energy $\mathrm{E}$ and frequency factor $A[6-8]$.

This experiment selects eucalyptus as experimental samples and studies biomass's pyrogenation kinetics and the features of volatile product on account of the heating rate variable. This study will provide theoretical basis for the problems of bed material deposited poly group, furnace slagging and 
equipment corrosion during biomass were burning. Then achieve the goal of optimization of pyrogenation reaction and process design.

\section{Experimental details}

\section{Appaatus and material}

EA3000 element analyzer, Perkins Elmer Pyris STA6000 thermogravimetric analyzer and Spectrum-1 Fourier transformation infrared Spectrum analyzer were used in the current work. Chose eucalyptus which come from Guangdong Zhanjiang biomass power plants as the sample. The industrial analysis and elemental analysis of eucalyptus were listed in table 1. In order to reduce the effects of heat transfer in the process of pyrogenation, we decided sample loading $10 \mathrm{mg}$ each time, particle size of $0.08-0.10 \mathrm{~mm}$, carrier gas flow rate of $100 \mathrm{~mL} \cdot \mathrm{min}^{-1}$ and the concentration of $99.995 \%$ of the nitrogen gas as shielding gas. Study the pyrogenation kinetics properties at the heating rate of $10^{\circ} \mathrm{C} \cdot \mathrm{min}^{-1}$ 、 $30^{\circ} \mathrm{C} \cdot \mathrm{min}^{-1} 、 60^{\circ} \mathrm{C} \cdot \mathrm{min}^{-1}$ respectively.

Table 1 The industrial analysis and elemental analysis of eucalyptus

\begin{tabular}{llccc|ccccc}
\hline \multirow{2}{*}{ Eucalyptus } & \multicolumn{4}{c|}{ Industry analysis (\%) } & \multicolumn{4}{c}{ Elemental analysis (\%) } \\
\cline { 2 - 10 } Percentage & Water & Ash & Volatile & Fixed carbon & N & C & H & O & S \\
\cline { 2 - 10 } & 11.97 & 19.70 & 53.13 & 15.18 & 0.23 & 45.78 & 5.23 & 34.88 & 13.87 \\
\hline
\end{tabular}

\section{Experimental methods}

Took a certain amount of eucalyptus, and got biomass granule by using mini crusher for plants. Screened out particles of $0.08-0.10 \mathrm{~mm}$. Using analytical balance to weigh the quality of $30 \mathrm{mg}$ samples, and divided the samples into three averagely, called A, B, and C, respectively. Set the experimental conditions as carrier gas flow rate of $100 \mathrm{~mL} \cdot \mathrm{min}^{-1}$, atmospheric pressure state, $99.995 \%$ concentration of nitrogen as shielding gas. Set the heating rate of $10^{\circ} \mathrm{C} \cdot \mathrm{min}^{-1}, 30^{\circ} \mathrm{C} \cdot \mathrm{min}^{-1}$ and $60^{\circ} \mathrm{Cmin}^{-1}$ respectively for temperature thermogravimetric analysis. Real-time monitoring eucalyptus weightlessness rate and volatile products quantity of precipitation in the process of the pyrogenation by using Perkin Elmer Pyris STA6000 thermogravimetric analyzer and Spectrum-1 fourier transformation infrared Spectrum analyzer. Maped TG-DTG curves and FTIR spectra under different heating rate.

\section{Results and discussion}

\section{TG-DTG thermogravimetric results of eucalyptus}

The thermal gravity analysis (TG) and differential thermal gravity (DTG) of eucalyptus under the heating rate of $10^{\circ} \mathrm{C} \cdot \mathrm{min}^{-1}, 30^{\circ} \mathrm{C} \cdot \mathrm{min}^{-1}$ and $60^{\circ} \mathrm{C} \cdot \mathrm{min}^{-1}$ are shown in figure 1 and figure 2 . The pyrogenation process of eucalyptus under the different heating rate are almost the same. The process are mainly divided into three obvious stages, namely: moisture evaporation stage $\left(0-265^{\circ} \mathrm{C}\right)$, volatile analysis stage $\left(265-605^{\circ} \mathrm{C}\right)$, carbonized stage $\left(605-700^{\circ} \mathrm{C}\right)$.

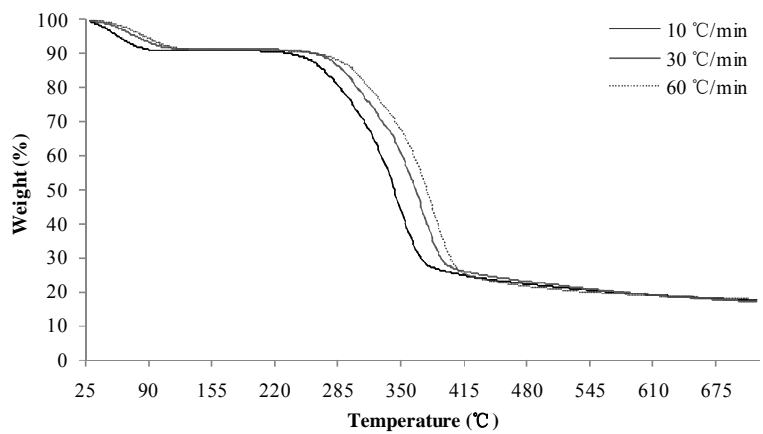

Fig.1 TG curves of eucalyptus at different heating rates

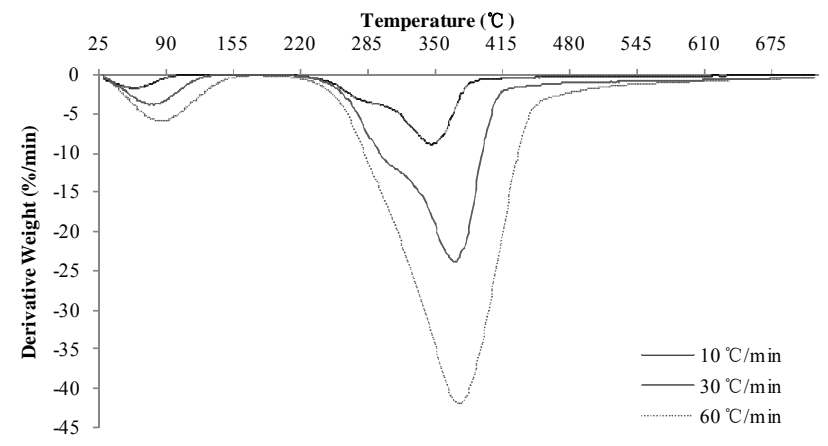

Fig.2 DTG curves of eucalyptus at different heating rates 


\section{The analysis of results of TG-DTG of eucalyptus stem}

Figure 1 and figure 2 reflect the overall trend of sample in the process of pyrogenation.It can be seen from the figure 1 that the first stage is the water volatilizing. In this phase, the surface and interior free water of sample evaporate. The temperature span of when the water volatilizes is less than $265^{\circ} \mathrm{C}$. The loss of weight is between $8.66 \%$ and $9.15 \%$ under three different heating rate. In this process, the main work is to dry and preheat the sample of eucalyptus. With the increase of temperature $\left(>265^{\circ} \mathrm{C}\right)$, volatile begin to precipitate and burning. The sample lose weight quickly. When the temperature span is $265-605^{\circ} \mathrm{C}$, the loss of weight is between $68.23 \%$ to $69.16 \%$. At this point, the loss of weight span in this stage is wider than that of other two stages. The above phenomenon is due to the mainly cellusose, hemicelluloses and part of lignin in eucalyptus decompose at this stage. At the same time, a series of complex and continuous parallel thermal chemical reaction appear in this stage. The phase is known as volatile analysis stage. It is the most important stage in the whole process of pyrogenation[9-12]. When the temperature is higher than $605^{\circ} \mathrm{C}$, the loss of weight rate decline gradually until the leveling off. The terminate temperature is $700^{\circ} \mathrm{C}$. This phase is known as coking stage. With the increase of heating rate, time to reach the terminate temperature is shorter gradually. Final residual amount has a small gap under different heating rate.

It can seen from the curve ofDTG shown in figure 2 that, in the water evapotating stage, the heating rate is $-1.80 \% \cdot \mathrm{min}^{-1},-3.85 \% \cdot \mathrm{min}^{-1}$ and $-5.96 \% \cdot \mathrm{min}^{-1}$ respectively under the maximum loss of weight rate in $10^{\circ} \mathrm{C} \cdot \mathrm{min}^{-1}, 30^{\circ} \mathrm{C} \cdot \mathrm{min}^{-1}$ and $60^{\circ} \mathrm{C} \cdot \mathrm{min}^{-1}$ respectively. In the precipitate stage of volatile products, the heating rate is $-8.90 \% \cdot \mathrm{min}^{-1},-23.95 \% \cdot \mathrm{min}^{-1}$ and $-41.89 \% \cdot \mathrm{min}^{-1}$ respectively under the maximum loss of weight rate in $10^{\circ} \mathrm{C} \cdot \mathrm{min}^{-1}, 30^{\circ} \mathrm{C} \cdot \mathrm{min}^{-1}$ and $60^{\circ} \mathrm{C} \cdot \mathrm{min}^{-1}$ respectively. There is a shoulder peak which represents the decomposition of hemicelluloses under $301.20^{\circ} \mathrm{C}$ and the maximum peak which represents the decomposition of cellulose under $346.83^{\circ} \mathrm{C}$ at the heating rate of $10^{\circ} \mathrm{C} \cdot \mathrm{min}^{-1}$. After $580^{\circ} \mathrm{C}$, the loss of weight rate decline gradually corresponds to the decomposition of lignin or coke, and much coke are left. However, the shoulder peak which represents the decomposition of hemicelluloses become unsignificant gradually under the heating rate of $30^{\circ} \mathrm{C} \cdot \mathrm{min}^{-1}$ with the improvement of heating rate. When the heating rate is $60^{\circ} \mathrm{C} \cdot \mathrm{min}^{-1}$, the shoulder peak disappear. This is mainly due to the increasing of heating rate provide more heat, and it make the heat around the sample transfer into the inside more easily. Therefore, the increasing of heating rate not only reduce the time that the sample achieve the ash volatile stage, but also increase the exterior temperature difference, which make the pyrogenation gas of outer layer cannot spread in time and aggravate thermal hysteresis phenomenon[13].

\section{Model fitting of active energy in the process of pyrolusis}

The biggest advantage of Flynn-Wall-Ozawa method is that calculating active energy not involve the choice of reaction mechanism and getting the results with on function. This method can avoid the possible error carried by choosing reaction mechanism. In addition, Flynn-Wall-Ozawa method is rarely for biomass. Therefore, we choose Flynn-Wall-Ozawa method for study. The fitting equation as follow:

$$
\lg \beta=\lg \left[\frac{A E}{R G(\alpha)}\right]-2.315-0.4567 \frac{E}{R T}
$$

Where $\alpha$-conversion rate; t-break time, min; T-absolute temperature, $\mathrm{T} ; \mathrm{A}$-refers to the former factor, $\min ^{-1}$; E-the reaction activation energy, $\mathrm{kJ} \cdot \mathrm{mol}^{-1}$; $\mathrm{R}$-gas constant, $\mathrm{R}=8.315 \mathrm{~mol} \cdot \mathrm{K}^{-1} ; \beta$-heating rate, ${ }^{\circ} \mathrm{C} \cdot \min ^{-1}$.

The fitting linear relationship of $\lg \beta \sim \frac{1}{T}$ are shown in table 2 . 
Table 2 The activation energy E value of eucalyptus under different circumstances at $\beta=30^{\circ} \mathrm{C} \cdot \mathrm{min}^{-1}$

\begin{tabular}{ccc}
\hline \multirow{2}{*}{$\alpha / \%$} & \multicolumn{2}{c}{ Flynn-Wall-Ozawa } \\
\cline { 2 - 3 } & $\mathrm{E} / \mathrm{kJ}^{2} \mathrm{~mol}^{-1}$ & $\mathrm{R}^{2}$ \\
\hline 0.2 & 33.25 & 0.998 \\
0.4 & 46.05 & 0.979 \\
0.6 & 52.88 & 0.983 \\
0.8 & 60.12 & 0.978 \\
\hline
\end{tabular}

As shown in table 2, the activation energy of pyrogenation increases with the increase of conversion rate when $\alpha \in[0.2,0.8]$. The principal cause of this phenomenon is the large release of hemicelluloses, cellulose and other components. With the increase of temperature, a large number of polymer long chain of cellulose begin to pyrolysis. The pyrolytic reaction mechanism of eucalyptus can be described by random nucleation mechanism function $(n=2)$, because the activation energy of cellulose is higher than that of hemicelluloses (Fig. 3).

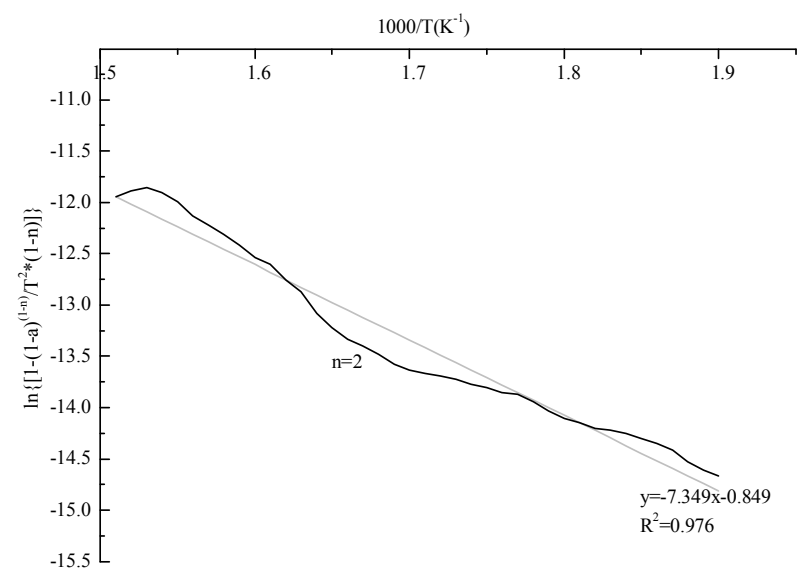

Fig. 3 The kinetic analysis of random nucleation of eucalyptus $(\mathrm{n}=2)$

The activation energy calculated by Flynn-Wall-Ozawa method is between $33.25 \mathrm{~kJ} \cdot \mathrm{mol}^{-1}$ to $60.12 \mathrm{~kJ} \cdot \mathrm{mol}^{-1}$. The results have little difference compared with that calculated by $\mathrm{C}-\mathrm{R}$ method. Therefore, using Flynn-Wall-Ozawa method can meet the requirements of the experimental datas, and it can also examine the rationality of the assumption of reaction mechanism function.

\section{The analysis of thermal conversion products precipitating based on FTIR}

When the temperature is $10^{\circ} \mathrm{C}, 30^{\circ} \mathrm{C}$ and $60^{\circ} \mathrm{C}$ respectively, the characteristic peaks of $\mathrm{H}_{2} \mathrm{O}, \mathrm{CO}_{2}$, $\mathrm{CO}, \mathrm{CH}_{4}$ and some oxygen compounds in the thermal conversion process are shown in figure 4 to figure 6[14-17]. A continuous low peak occur when the wavenumber is in the rage of $3500 \mathrm{~cm}^{-1}$ to $3950 \mathrm{~cm}^{-1}$. It means that the $\mathrm{O}-\mathrm{H}$ keys in the water vapor molecules stretching vibrating in the way of symmetry and asymmetric. The weight loss process of this functional groups in the first stage $\left(0-265^{\circ} \mathrm{C}\right)$ is the same as that in the moisture evaporation stage shown in the curve of TG-DTG. In addition, the unimodal at the wavenumber of $670 \mathrm{~cm}^{-1}$ occurs in the whole process of pyrogenation. The main reason is there is decarboxylation of eucalyptus generating $\mathrm{CO}_{2}$. For the strong absorption band (wavenumber ranged from $1000 \mathrm{~cm}^{-1}$ to $1800 \mathrm{~cm}^{-1}$ ), it mainly involves spirituous C-H-O keys of saturated carbon absorption (wavenumber ranged from $1030 \mathrm{~cm}^{-1}$ to $1100 \mathrm{~cm}^{-1}$ ), C-O keys which phenolic hydroxyl and oxygen stretching vibrating absorption peak (wavenumber ranged from $1185 \mathrm{~cm}^{-1}$ to $1240 \mathrm{~cm}^{-1}$ ) and $\mathrm{C}=\mathrm{O}$ keys which carboxylic acids or carboxylic compounds (such as aldehydes, ketones and esters) stretching vibrating absorption peak (wavenumber ranged from $1580 \mathrm{~cm}^{-1}$ to $1800 \mathrm{~cm}^{-1}$ ). As a result, the wave peaks within the wavenumber above represent absorption band and characteristic peak which caused by macromolecules functional groups such as aldehydes, ketones,carboxylic acid, phenol and alcohol. The twin peak in the rage of $2250 \mathrm{~cm}^{-1}$ to $2021 \mathrm{~cm}^{-1}$ in the figure is very clear. This is caused by $\mathrm{C}-\mathrm{O}$ absorption peak of $\mathrm{CO}$ which producted by incompleting of macromelecular organic compounds in the process of pyrogenation. Some absorption band caused by small molecular alkyl groups appear in the rage of $2620 \mathrm{~cm}^{-1}$ to $3120 \mathrm{~cm}^{-1}$. For example, $\mathrm{CH}_{3}^{-}, \mathrm{CH}_{2}^{-}$and $\mathrm{CH}^{-}$which stretching vibrating in the 
way of symmetric and anti-symmetric. The small molecular conmpounds such as acetic, formic acid, small molecular alkanes, olefin and alkyne in this absorption band[18]. When the temperature is higher than $360^{\circ} \mathrm{C}$, there is a clear absorption peak at the wavenumber of $3014 \mathrm{~cm}^{-1}$. The peak in this place represents the break of macromolecular keys and reconstruction of different organic functional groups in the process of pyrogenation.
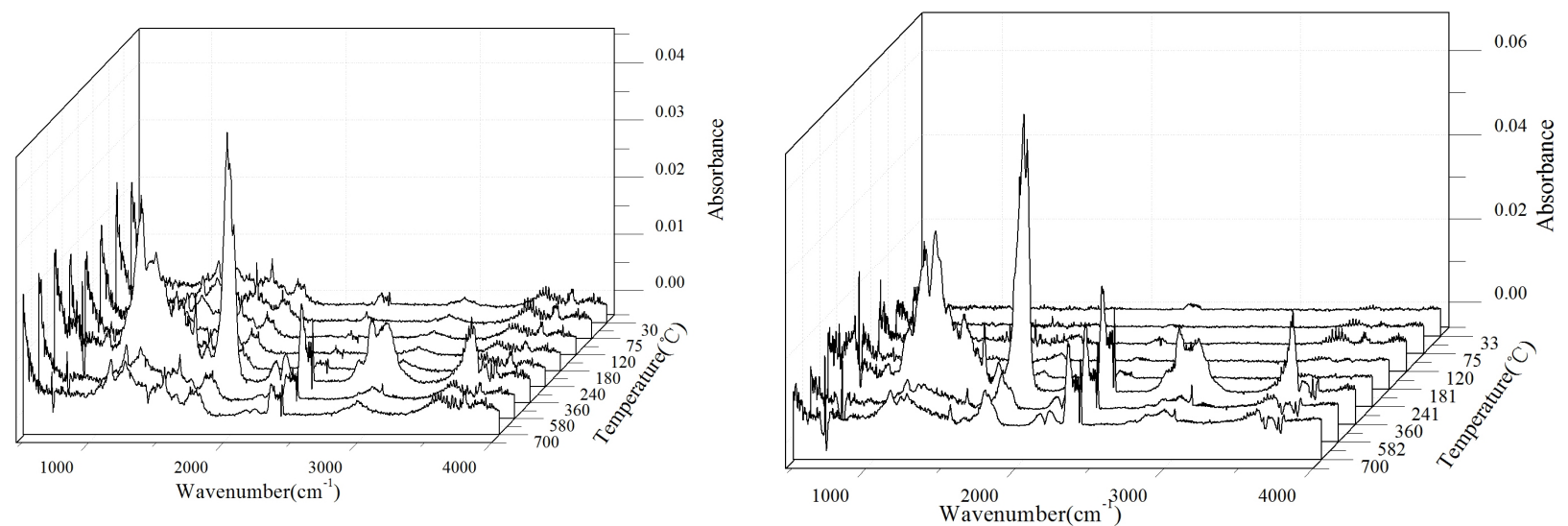

Fig.4 The FTIR spectra of eucalyptus volatile products at $\beta=10^{\circ} \mathrm{C} \cdot \mathrm{min}^{-1}$ Fig.5 The FTIR spectra of eucalyptus volatile products at $\beta=30^{\circ} \mathrm{C} \cdot \mathrm{min}^{-1}$

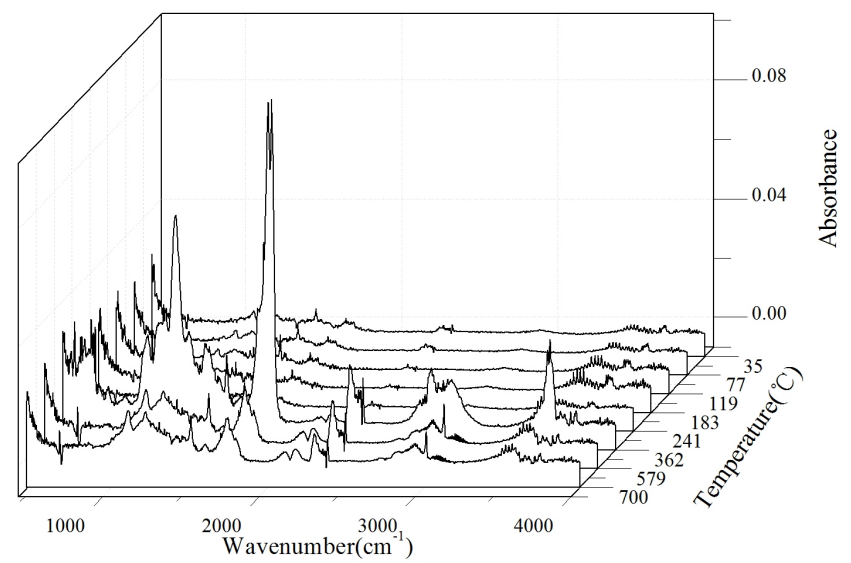

Fig. 6 The FTIR spectra of eucalyptus volatile products at $\beta=60^{\circ} \mathrm{C} \cdot \mathrm{min}^{-1}$

\section{The research on slagging mechanism based on the analysis of volatile products of eucalyptus}

In moisture volatilizes stage, the free water in eucalyptus will evaporate with the rising of temperature. The samples of eucalyptus become very dry. The dry samples absorb heat continuously. When the temperature reaches the rage of $110^{\circ} \mathrm{C}$ to $265^{\circ} \mathrm{C}$, volatile gas in the surface of eucalyptus is further precipitated and the original structure of eucalyptus begin to be destroyed. Then eucalyptus becomes fluffy. When the temperature is higher than $265^{\circ} \mathrm{C}$, saturated carbon alcohols, saturated esters, saturated aldehydes, saturated ketones, saturated hydrocarbon begin to burning and produce heat. Part of heat transfer into the atmosphere. Another part of heat spread to the interior of eucalyptus and make inner volatile being precipitated further. Volatile cocoon the rest of the coke and cut off the contact between coke and oxygen. Coke start to contact with oxygen slowly with volatile combusting and reducing. There is a lot of ash in the process of coke burning, which make the fuel to be cocooned. It prevent coke burning continuously. This causes large numbers of slagging phenomenon and leads to low efficiency or shutdown of furnace. According to the characteristic of volatile of eucalyptus producted in the process of pyrolysis, the slagging mechanism is explored. It provides the basis for optimizing the corresponding combustion equipments and process design. 


\section{Conclusion}

(1)The experiment of pyrgenation dynamics analysis showed that the loss of weight progress was divided into moisture bolatilizes stage, volatile precipitating stage and carbonization stage. The main reaction stage mainly concentrated in the volatile precipitating stage. The largest loss of weight increased with the increasing of heating rate. The pyrogenation curves of main reaction moved to high temperature shown in the curve of TG. The maximum peak temperature of the maximum heating rate moved to high temperature slightly shown in the curve of DTG.

(2)The activation energy calculated by Flynn-Wall-Ozawa method was between $33.25 \mathrm{~kJ} \cdot \mathrm{mol}^{-1}$ to $60.12 \mathrm{~kJ} \cdot \mathrm{mol}^{-1}$. The results had little difference compared with that calculated by $\mathrm{C}-\mathrm{R}$ method.

(3)The FTIR spectra showed stretching the vibration characteristic peak and absorption peak of $\mathrm{O}-\mathrm{H}, \mathrm{C}=\mathrm{O}, \mathrm{C}-\mathrm{O}-\mathrm{H}, \mathrm{H}-\mathrm{O}-\mathrm{C}=\mathrm{O}$ and small molecular alkyl groups in different wavenumbers. The characteristic peak and absorption band of every kind of volatile were accordance with the curve of FG-DTG. The test verified the products in each pyrogenation stage.

(4)Analyzing the characteristic of volatile products by using TG-DTG-FTIR method was helpful to study the slagging mechanism in three stages. It achieved the purpose of optimizing the existing combustion equipments and parameters of the process gradually.

\section{References}

[1] Shi Changdong, Zhang Rui, Che Deyong, Jiajia, in: Research on pyrolysis characteristics about different types of biomass. (2012)

[2] Zhan Huilong, Yan Changyu, Yang Zhao, in: Research on the development of Chinese agricultural biomass industry. (2010)

[3] Zhao Jun, in: The utilization of biomass energy resources in our country. (2008)

[4] Wang Jiuchen, in: Current situation of the development trend analysis about Chinese Biomass Industry. (2007)

[5] Christian Ahl, in: Biomass energy in a small-scale region of a developed country - the case of the district of Goettingen. (2000)

[6] Michal Tou, in: Effective biomass integration into existing combustion plant. (2011)

[7] Su Qiong, in: Pyrolysis influencing factors about cellulose biomass. (2007)

[8] Kloprogge J T, Ruan H D, Frost R L, in: Thermal decomposition of bauxite minerals: infrared emission spectroscopy of gibbsite, boehmite and diaspore. (2002)

[9] Kirtania K, Bhattacharya S, in: Application of the distributed activation energy model to the kinetic study of pyrolysis of the fresh water algae Chlorococcum humicola. (2012)

[10] Yue Maozhen, Wang Yongzheng, Bian Sufang, Tian Sule, Lu Chen, in: Biomass and coal combustion in the process of corrosion and its prevention measures. (2012)

[11] Wang Shuang, Jiang Xiumin, in: The test and mechanism research of algae biomass pyrolysis and combustion. (2010)

[12] Lai Yanhua, Lv Mingxin, Ma Chunyuan, Shi Mingheng, in: Research on pyrolysis characteristics and kinetics about the straw raw material. (2002)

[13] We Wei, Huang Fang, Yu Chunjiang, Fang Mengxiang, in: Biomass combustion equipment around high temperature corrosion problems. (2011)

[14] Bojan Janković, Ivana Smičiklas, Jasna Stajić-Trošić, Dušan Antonobić, in: Thermal characterization and kinetic analysis of non-isothermal decomposition process of Bauxite red mud. Estimation of density distribution function of the apparent activation energy. (2013)

[15] Sun Ying, Wang Yongzheng, Su Xiujuan, in: Research on biomass combustion, slagging and sulphuric acid corrosion features. (2011)

[16] M. Varol, A.T. Atimtay, B. Bay, H. Olgun, in: Investigation of co-combustion characteristics of low quality lignite coals and biomass with thermogravimetric analysis. (2010)

[17] K.G. Mansaray, A.E. Ghaly, in: Kinetics of the thermal degradation of rice husks in nitrogen atmosphere. (1999)

[18] Si Yaohui, in: Agricultural straw combustion characteristic and dynamics analysis. (2012) 